\title{
Mediastinal hydatid cyst: an unusual case report
}

\author{
Najat Id el haj ${ }^{1,2}$, Souheil Boubia ${ }^{1,2}$, Mohammed Ridai ${ }^{1,2}$ \\ ${ }^{1}$ Department of Thoracic Surgery, University Hospital Center Ibn Rochd Casablanca, Casablanca, Morocco; ${ }^{2}$ Hassan 2 University of Casablanca, \\ Casablanca, Morocco \\ Correspondence to: Najat Id el haj. 49 Street 28, First Floor, Hay El Mesjid, Casablanca, Morocco. Email: najatidelhaj@yahoo.fr.
}

\begin{abstract}
Hydatid disease is a zoonosis caused by Echinococcus granulosus and remains a serious problem in Mediterranean countries. Mediastinal hydatid cyst is very rare. It is difficult to make the diagnosis of mediastinal hydatid cyst based only on clinical outcomes. Although many cases are diagnosed accidentally, some patients may have associated complications. Nevertheless, echinococcosis should be considered in patients with a mediastinal mass in endemic areas. Our case report is a 51-year-old woman, with no particular pathological history. Admitted to our department for management of a mediastinal injury, revealed by cough, dyspnea and chest pain, weight loss, fever, and night sweats. Chest X-Ray and chest CT showed an anterior mediastinal cystic lesion with a calcified wall. A diagnostic and therapeutic thoracotomy was performed first time leaving the sternotomy in second alternative view the risk of recurrence of this disease. The resection of this calcified mass, so hard and calcified, which facilitated the dissection without the risk of accidental rupture Histological examinations from the operative specimen confirmed hydatid cyst. The primary hydatid cyst of the mediastinum is a disease to be taken into account in the management of a patient with a mediastinal mass and living in an endemic area. Because of the surrounding vital structures, surgery must be done without delay.
\end{abstract}

Keywords: Mediastinal; hydatid cyst; rare; surgery; case report

Received: 30 March 2019; Accepted: 04 March 2021; Published: 20 July 2021.

doi: 10.21037/jovs-19-69

View this article at: http://dx.doi.org/10.21037/jovs-19-69

\section{Introduction}

Hydatid disease is still a public health problem in Mediterranean countries, such as Morocco. Living in a rural area is an important risk factor. Hydatid cyst is caused by the larval form of Echinococcus granulosus, it's located in the liver, lung and brain, but the mediastinal location is very rare that were anecdotally reported in the literature, less than $0.1 \%$ (1).

A review of the literature indicates that there is not enough consensus on diagnosis and management. Although it appears there is agreement on some therapeutic aspects. These findings are often based on limited data considering its rarity (2).

Controversial issues concerning surgical management of mediastinal hydatid cysts; include indication of surgery, specific procedures performed, and optimal approach (thoracotomy, sternotomy, open minimally invasive) $(1,3)$. Therefore, in our case report, we have to evaluate the clinical, diagnostic, and surgical problems of this entity with review of the literature. We present the following article in accordance with the CARE reporting checklist (available at https://jovs.amegroups.com/article/ view/10.21037/jovs-19-69/rc).

\section{Case presentation}

A woman aged 51, living in a rural area. No previous personal surgical or family history. She was admitted to our center with a respiratory symptom made of dyspnea, cough, and chest pain, associated with weight loss, fever, night sweats for 2 months. The general examination as well as the pleuropulmonary examination are unremarkable. Chest X-ray demonstrated homogeneous dense hilary right opacity (Figure 1).

A computed tomography (CT) chest scan showed fairly 
calcified well defined cystic mediastinal mass. The cyst had contact with the vena cava superior and the aortic arch (Figure 2).

Bronchoscopy revealed normal. Pulmonary function test results showed obstructive ventilary disorder with a forced expiratory volume in one second of $68 \%$. Abdominal ultrasound did not show other localizations. Hydatid serology was negative. Routine hematological test was within normal. After having informed consent from the patient, a diagnostic and therapeutic thoracotomy is instituted. A right posterolateral thoracotomy of $7 \mathrm{~cm}$ with muscles section to give a better day to the mediastinal cystic

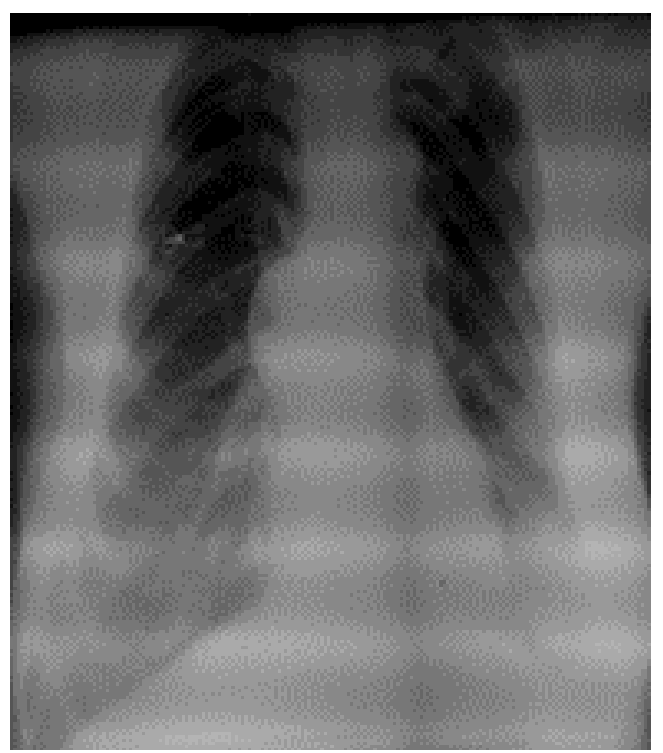

Figure 1 Homogeneous dense hilary right opacity. lesion through the fifth intercostal space, was perform, leaving sternotomy as the first channel of last resort because of the recurrent nature of the hydatid cyst. The mass was identified with calcified spherical margin and located in the superior mediastinum, extending to the vena cava superior and the right auricle. There were a lot adhesions with lung, the mediastinum and symphysis apical. Adhesiolysis was difficult but easy with thoracotomy. After the adhesiolysis, minimal bleeding is causing or hemostasis is ensured by coagulation clamp, and we have no intraoperative blood transfusion. After dissected from the surrounding structures: the ventral segment of the upper right lobe, the superior vena cava and a small part of pericardium, the intervention consisted of a resection of this calcified mass, so hard and calcified the capsule helped us to solve it without breaking it (Figure 3).

The pathology examination of the operative specimen confirmed the diagnosis of hydatid cyst. The patient did not receive Albendazole because the hydatid cyst was not ruptured. She recovered without postoperative complications, with a four-day hospital stay and no recurrence during a seven-year follow-up. All procedures performed in this study were in accordance the ethical standards of the institutional and/or national research committee(s) and with the Helsinki Declaration (as revised in 2013). Written consent was obtained from the patient for the publication of this manuscript.

\section{Discussion}

The mediastinal hydatid cysts are uncommon, the parasite is located after liver and lung filters, probably via an arterial
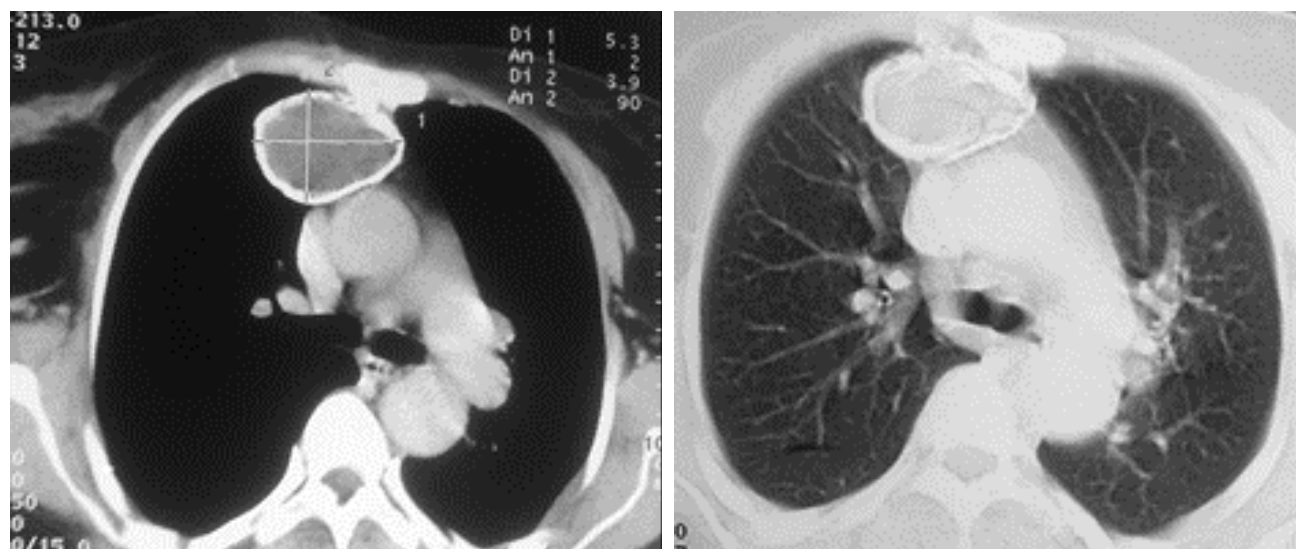

Figure 2 Fairly calcified well defined cystic mediastinal mass. The cyst had contact with the vena cava. 


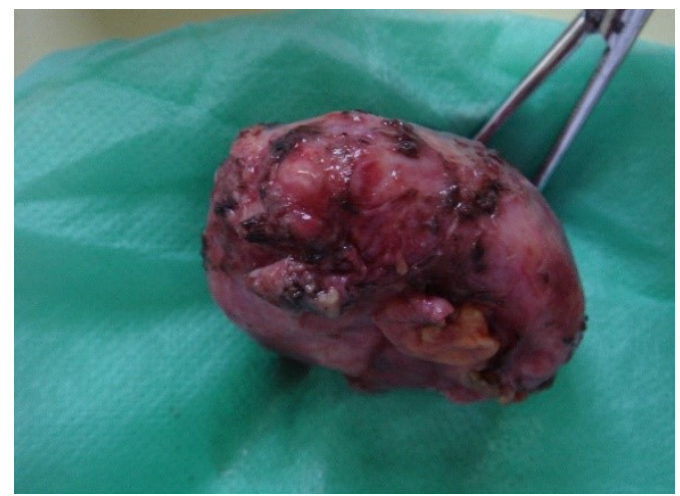

Figure 3 The operative piece of the calcified mediastinal mass.

branch of the thoracic aorta or lymphatic system (2).

Of the mediastinal hydatid cysts reported in the literature, an overwhelming majority were in the posterior mediastinum. The location of this cyst in the anterior and upper mediastinum is a rare clinical presentation. It most frequently progresses to calcification rather than a pulmonary hydatid cyst because there is no relationship with ventilation (4).

Mediastinal hydatid cyst is usually unique; multiple character is caused by trauma, rupture or thoracic surgery of a primary hydatid cyst. Although hydatid cysts may be asymptomatic, they can usually manifest as various symptoms; secondary to a compressive effect on the surrounding vital structures, such as dyspnea, retrosternal chest pain, cough, dysphagia, back pain and superior vena cava syndrome (3).

The most severe complications are the invasion of the aorta, and anaphylactic shock due to an allergic reaction to the cyst (5). Our patience is mainly chest pain, cough, dyspnea, weight loss, fever and night sweats following a hydatid cyst infection.

The hydatid serology can provide diagnostic elements in a large number of cases, and monitor the therapeutic efficacy (6).

Chest radiography and CT are the most commonly used of mediastinal hydatid cyst diagnostic modalities. CT is essential and important to show the morphology, density and limitations of these lesions. The presence of calcifications must think hydatid cyst, as in our case report (7). Chest magnetic resonance imaging can be used to study the relationship with adjacent structures, particularly spinal involvement in cases where the cyst is in the posterior mediastinum or where there is a neurological sign. An abdominal ultrasound is systematic, since the liver is the first hydatid localization and also look for other abdominal locations $(7,8)$.

Complications of mediastinal hydatid cyst can be serious and sometimes life-threatening patient (rupture, fistula, infection and compression of vital structures). For these reasons, surgery is indicated. The standard treatment is pericytectomy with removal of the germinal membrane by the appropriate thoracic approach $(6,9)$. When cyst localization and invasion of vital structures prevent total excision, partial pericystectomy is the treatment of choice after removal of the germinal membrane. The surgical approach is according, a video assisted thoracic surgery (VATS), a poster lateral thoracotomy, anterolateral thoracotomy or median sternotomy. The choice of surgical approach depends on the cyst location. Our patient was approached by poster lateral thoracotomy whose intervention consists of a resection of this calcified mass, even if it was very adherent to the mediastinum elements particularly in the vena cava superior.

The value of medical treatment based on albendazole remains controversial, it was given in postoperative especially in patients with dissemination signs or ruptured cyst (4). Our patient did not receive Albendazole because there is no evidence of hydatid cyst removal or rupture.

The postoperative course is classically simple with no mortality. No cases of recurrence have been described as it is in our observation with a decline of seven years. The postoperative outcome was adequate. His condition evolved favorably.

\section{Conclusions}

Mediastinal cyst hydatid is a very rare disease, which may manifest clinically by signs of compression in the endemic areas. Surgery is the radical treatment and must be done without delay in order to avoid or to lift the compression of the surrounding structures. Prevention remains the best way to eradicate this parasite.

\section{Acknowledgments}

Funding: None.

\section{Footnote}

Reporting Checklist: The authors have completed the CARE reporting checklist. Available at https://jovs.amegroups. com/article/view/10.21037/jovs-19-69/rc 
Conflicts of Interest: All authors have completed the ICMJE uniform disclosure form (available at https://jovs. amegroups.com/article/view/10.21037/jovs-19-69/coif). The authors have no conflicts of interest to declare.

Ethical Statement: The authors are accountable for all aspects of the work in ensuring that questions related to the accuracy or integrity of any part of the work are appropriately investigated and resolved. All procedures performed in this study were in accordance the ethical standards of the institutional and/or national research committee(s) and with the Helsinki Declaration (as revised in 2013). Written consent was obtained from the patient for the publication of this manuscript.

Open Access Statement: This is an Open Access article distributed in accordance with the Creative Commons Attribution-NonCommercial-NoDerivs 4.0 International License (CC BY-NC-ND 4.0), which permits the noncommercial replication and distribution of the article with the strict proviso that no changes or edits are made and the original work is properly cited (including links to both the formal publication through the relevant DOI and the license). See: https://creativecommons.org/licenses/by-nc-nd/4.0/.

\section{References}

1. Shameem M, Bhargava R, Ahmad Z, et al. Mediastinal

doi: $10.21037 /$ jovs-19-69

Cite this article as: Id el haj N, Boubia S, Ridai M. Mediastinal hydatid cyst: an unusual case report. J Vis Surg 2021;7:34. hydatid cyst rupturing into the pleural cavity associated with pneumothorax: Case report and review of the literature. Can Respir J 2006;13:211-3.

2. Eroğlu A, Aydın Y, Altuntaş B, et al. Surgical management of primary mediastinal hydatid cysts: a 30-year experience. Turk Gogus Kalp Dama 2016;24:495-500.

3. Eroğlu A, Kürkçüoğlu C, Karaoğlanoğlu N, et al. Primary hydatid cysts of the mediastinum. Eur J Cardiothorac Surg 2002;22:599-601.

4. Traibi A, Atoini F, Zidane A, et al. Mediastinal Hydatid. Cyst J Chin Med Assoc 2010;73:3-7.

5. Mohammadi A, Khodabakhsh M. Multiple mediastinal hydatic cysts: a case report. Tuberk Toraks 2011;59:70-2.

6. Goenka AH, Das CJ, Goel P, et al. Giant primary posterior mediastinal hydatid cyst in a child: report of a case and review of literature. Pediatr Surg Int 2009;25:647-9.

7. Eroğlu A, Kürkçüoğlu C, Karaoğlanoğlu N, et al. Primary hydatid cysts of the mediastinum. Eur J Cardiothorac Surg 2002;22:599-601.

8. Ozpolat B, Ozeren M, Soyal T, et al. Unusually located intrathoracic extrapulmonary mediastinal hydatid cyst manifesting as Pancoast syndrome. J Thorac Cardiovasc Surg 2005;129:688-9.

9. Zidi A, Zannad-Hantous S, Mestiri I, et al. Hydatid cyst of the mediastinum: 14 case reports. J Radiol 2006;87:1869-74. 